\title{
ANALISIS KOMPARASI METODE PERBAIKAN KONTRAS BERBASIS HISTOGRAM EQUALIZATION PADA CITRA MEDIS
}

\author{
Aditya Akbar Riadi \\ Fakultas Teknik, Program Studi Teknik Informatika \\ Universitas Muria Kudus \\ Email: aditya.akbar@umk.ac.id \\ Ahmad Abdul Chamid \\ Fakultas Teknik, Program Studi Teknik Informatika \\ Universitas Muria Kudus \\ Email: abdul.chamid@umk.ac.id \\ Akh. Sokhibi \\ Fakultas Teknik, Program Studi Teknik Industri \\ Universitas Muria Kudus \\ Email: akh.sokhibi@umk.ac.id
}

\begin{abstract}
ABSTRAK
Citra merupakan gambaran tentang karakteristik suatu obyek menurut kondisi variabel tertentu. Pengolahan citra bertujuan memperbaiki kualitas citra agar mudah diinterpretasi oleh manusia atau mesin (dalam hal ini komputer). Terdapat beberapa operasi di dalam pengolahan citra, salah satunya adalah perbaikan kontras yang pada dasarnya biasa digunakan untuk memunculkan bagian-bagian yang tidak terlihat (hidden feature) pada citra. Hasil citra dari rontgen yang tidak selalu memiliki kualitas citra yang baik, seperti halnya hasil citra $x$-ray yang terlalu gelap atau ada bagian tulang yang terlihat samar sehingga gambar tidak terlihat jelas. Pada penelitian ini teknik peningkatan citra dengan perbaikan kontras menggunakan metode berbasis Histrogram Equalization. Pada citra medis tersebut dan juga menunjukkan kinerja hasil pengukuran kontrol eror menggunakan Mean Square Error menjelaskan bahwa metode Contrast Limited Adaptive Histogram Equalization lebih baik dibandingkan dengan metode Histrogram Equalization dan metode Adaptive Histogram Equalization.
\end{abstract}

Kata kunci: perbaikan kontras citra, histogram equalization, adaptive histogram equalization, contrast limited adaptive histogram equalization, mean square error.

\section{ABSTRACT}

The image is a picture of the characteristics of an object according to certain variable conditions. Image processing aimed at improving the quality of the image to be easily interpreted by humans or machines (in this case the computer). There are several operations in image processing, one of which is the improvement of contrast is basically used to bring up the parts that are not visible (hidden feature) in the image. The results of $x$-ray images which do not always have a good image quality, as well as the results of $x$-ray image that are too dark or there is faintly visible part of the bone so that the image is not clearly visible. In this research technique with improved image contrast enhancement using histogrambased method of Equalization. In the medical image and also shows the results of performance measurement error control using the Mean Square Error explained that the method Contrast Limited Adaptive Histogram Equalization better than the histogram method and the method of Adaptive Histogram Equalization Equalization.

Keywords: image contrast improvement, histogram equalization, adaptive histogram equalization, contrast limited adaptive histogram equalization, mean square error.

\section{PENDAHULUAN}

Tujuan dari perbaikan citra adalah untuk menghasilkan prosedur penting dari pengolahan citra, prosedur ini adalah untuk merubah citra asli untuk lebih ditingkatkan tampilan kontrasnya untuk aplikasi tertentu. Teknik peningkatan Kontras akan memainkan peran penting dalam aplikasi pengolahan citra digital, seperti citra bergerak, foto digital, dan analisis citra medis, penginderaan jauh, dan berbagai citra ilmiah. Semua citra yang memiliki beberapa masalah seperti kontras yang buruk karena memiliki kualitas perangkat pencitraan atau pencahayaan yang berlebih. Sehingga kami mengusulkan teknik peningkatan kontras baru yang bertujuan untuk menghilangkan jenis masalah. Teknik peningkatan kontras yang berbeda digunakan untuk meningkatkan kontras citra seperti histogram 
equalization, modifikasi histogram, algoritma greedy, adaptive histogram equalization, dan lain sebagainya. Makalah ini menyajikan pendekatan baru untuk peningkatan kontras berdasarkan metode contrast limited adaptive histogram equalization.

\section{METODOLOGI PENELITIAN}

Teknik peningkatan kontras banyak tersedia dan menghasilkan citra yang tidak jelas, sehingga pertama kita membahas beberapa teknik peningkatan kontras yang diantaranya adalah :

\subsection{Histogram Equalization}

Tujuan dari histogram equalization adalah untuk mendistribusikan tingkat abu-abu dalam sebuah citra sehingga setiap tingkat abu-abu sama mungkin terjadi. Histogram equalization akan meningkatkan kecerahan dan kontras dari citra kontras gelap dan rendah.

Membuat fitur diamati yang tidak terlihat dalam citra asli. Hal ini juga digunakan untuk membakukan kecerahan dan kontras citra proses perataan histogram adalah untuk menemukan fungsi pemetaan yang memetakan fungsi histogram input citra ke fungsi output histogram terdistribusi secara merata.

Histogram equalization juga digunakan dalam jaringan saraf biologis sehingga memaksimalkan tingkat output yang menembakkan neuron sebagai fungsi statistik masukan. Ini telah terbukti khususnya di retina mata. [1] Pemerataan histogram adalah kasus khusus dari kelas yang lebih umum dari metode histogram remapping. Metode ini berusaha untuk menyesuaikan citra untuk membuatnya lebih mudah untuk menganalisis atau meningkatkan kualitas visual.

\subsection{Adaptive Histogram Equalization}

Biasanya histogram equalization menggunakan transformasi yang sama berasal dari histogram citra untuk mengubah semua piksel. Ini bekerja dengan baik ketika distribusi nilai piksel mirip keseluruh citra.

Namun, ketika citra berisi daerah yang secara signifikan lebih terang atau lebih gelap dari sebagian besar citra, kontras di daerah-daerah tidak akan cukup ditingkatkan. Adaptive Histogram Equalization (AHE) meningkatkan pada ini dengan mengubah setiap piksel dengan fungsi transformasi yang berasal dari daerah lingkungan. [3]

Ketika wilayah citra yang berisi lingkungan piksel ini cukup homogen, histogramnya akan sangat memuncak, dan fungsi transformasi akan memetakan kisaran sempit nilai piksel untuk seluruh jajaran citra hasil. Hal ini menyebabkan AHE untuk lebih memperkuat sejumlah kecil kebisingan di daerah sebagian besar homogen citra. [4]

Metode ini digunakan untuk meningkatkan kontras citra. Ini bervariasi dari histogram pemerataan dengan hormat bahwa metode adaptif membuat perhitungan beberapa histogram, setiap sesuai dengan bagian yang berbeda dari citra, dan gunakan untuk mengalokasikan nilai-nilai ringan dari citra. Oleh karena itu mudah untuk meningkatkan kontras lokal dari suatu citra dan menyampaikan lebih detail.

\subsection{Contrast Limited Adaptive Histogram Equalization}

Algoritma CLAHE (Contrast Limited Adaptive Histogram Equalization) yang diusulkan khusus dikembangkan untuk citra medis dan meningkatkan citra yang lebih baik dari citra asli. Algoritma CLAHE mempartisi citra ke daerah kontekstual dan menerapkan pemerataan histogram untuk masing-masing nilai piksel citra. CLAHE ini menghasilkan distribusi nilai abu-abu yang digunakan dan dengan demikian membuat fitur tersembunyi dari citra lebih terlihat. CLAHE adalah penulisan algoritma ditingkatkan dari AHE.

CLAHE merupakan generalisasi dari AHE (Adaptive Histogram Equalization). Berbeda dengan HE (Histogram Equalization) yang beroperasi pada keseluruhan region pada citra, CLAHE beroperasi pada region kecil pada citra grayscale yang disebut dengan tile. Kontras pada setiap tile diperbaiki sehingga histogram yang dihasilkan dari region tersebut kira-kira cocok dengan bentuk histogram yang ditentukan. Nilai piksel yang saling bertetangga disambungkan dengan menggunakan interpolasi bilinear. Hal ini dilakukan agar hasil penggabungan tile terlihat halus.

Perhitungan histogram untuk masing-masing daerah secara langsung. Dalam hal ini, koleksi jumlah nilai piksel ini untuk semua grayscales disebut sebagai histogram dari wilayah itu. Fungsi ini secara umum diperoleh dengan menggunakan perhitungan CDF (Cumulative Distribution Function). Jika jumlah piksel dan grayscales, di setiap daerah, masing-masing $\mathrm{M}$ dan $\mathrm{N}$, dan jika hi, $\mathrm{j}(\mathrm{n})$, untuk $\mathrm{n}=0,1,2, \ldots, \mathrm{N}-1$, adalah histogram $(\mathrm{i}, \mathrm{j})$ wilayah, maka perhitungan CDF sesuai, baik skala oleh $(\mathrm{N}-1)$ untuk pemetaan grayscale, adalah: 


\section{$f_{h f}(n)=\frac{(k-1)}{M}, \sum_{k=0}^{n} h_{i j}(k)$}

Fungsi persamaan (1) ini digunakan untuk mengubah fungsi kepadatan pada citra grayscale. Prosedur ini disebut sebagai pemerataan histogram. Masalah dengan metode ini adalah bahwa daerah kontras meningkat secara maksimal. Untuk membatasi nilai kontras ke tingkat yang diinginkan adalah dengan pendekatan dalam membatasi kemiringan nilai maksimum menggunakan nilai batas $\beta$ untuk perpotongan semua histogram. Nilai batas (cliplimit) ini dapat berhubungan dengan apa yang disebut sebagai clipfactor, $\alpha$ dalam persen, sebagai berikut.

$$
\beta=\frac{M}{N}\left(1+\frac{\pi}{108}\left(s_{\max }-1\right)\right)
$$

Dalam hal ini, persamaan (2) untuk clipfactor dari nol persen, maka $\alpha=0$ nilai batas menjadi sama dengan ukuran total citra, yang menghasilkan menjadi pemetaan nilai piksel dengan mendistribusikan semua piksel daerah ke semua grayscale secara merata. Tidak ada perubahan dalam nilai-nilai piksel akan terjadi dalam kasus ini. Batas maksimum klip, dicapai untuk $\alpha=100$, akan dirubah ke nilai maksimum $\left(s_{\max } \cdot \frac{M}{N}\right)$. Ini berarti, kemiringan

maksimum yang diijinkan adalah $s_{\max }$.

Tes citra dengan menggunakan algoritma yang diusulkan, Histogram Equalization, Adaptive Histogram Equalization \& ditingkatkan dengan nilai batas dari kontras histogram adaptif. teknik peningkatan ini dittunjukkan dengan hasil untuk citra seperti yang ditunjukkan pada contoh Citral. Dalam analisis visual teramati bahwa kontras telah ditingkatkan untuk berbagai tingkat oleh semua algoritma tetapi algoritma yang diusulkan meningkatkan citra lebih tepat dibandingkan dengan. Histogram Equalization, dan Adaptive Histogram Equalization.

\section{HASIL DAN PEMBAHASAN}

Pada bagian ini, hasil simulasi dari perbandingkan berbagai macam metode berbasis Histogram Equalization. Untuk menganalisis dan membandingkan metode yang ada kita gunakan sepuluh citra medis yang perbandingan visual dapat ditunjukkan pada Citra1.jpg sampai dengan citra Citra5.jpg.

Penilaian kualitatif dari peningkatan kontras diperlukan bersama dengan penilaian kuantitatif. Hasil perbaikan kualitas citra hanya dapat dihargai jika citra yang dihasilkan memberikan efek yang bagus dari tingkat pencahayaan yang cukup dalam penampilan citra asli. Dengan penilaian kualitas visual yang dimiliki pencahayaan yang kurang, harus lebih ditingkatkan atau dilakukan dengan peningkatan tidak wajar. Hasil penilaian visual ukuran kualitas yang efektif untuk menilai kinerja algoritma peningkatan kontras. Berikut hasil perbaikan kontras citra secara visual yang ditampilkan sebaikan mulai dari Citra1.jpg sampai Citra5.jpg.

\begin{tabular}{|c|c|c|c|c|}
\hline $\begin{array}{c}\text { Nama } \\
\text { Citra }\end{array}$ & Citra Asli & HE & AHE & CLAHE \\
\hline Citra1.jpg & & &
\end{tabular}


Jurnal SIMETRIS, Vol 8 No 1 April 2017

ISSN: 2252-4983

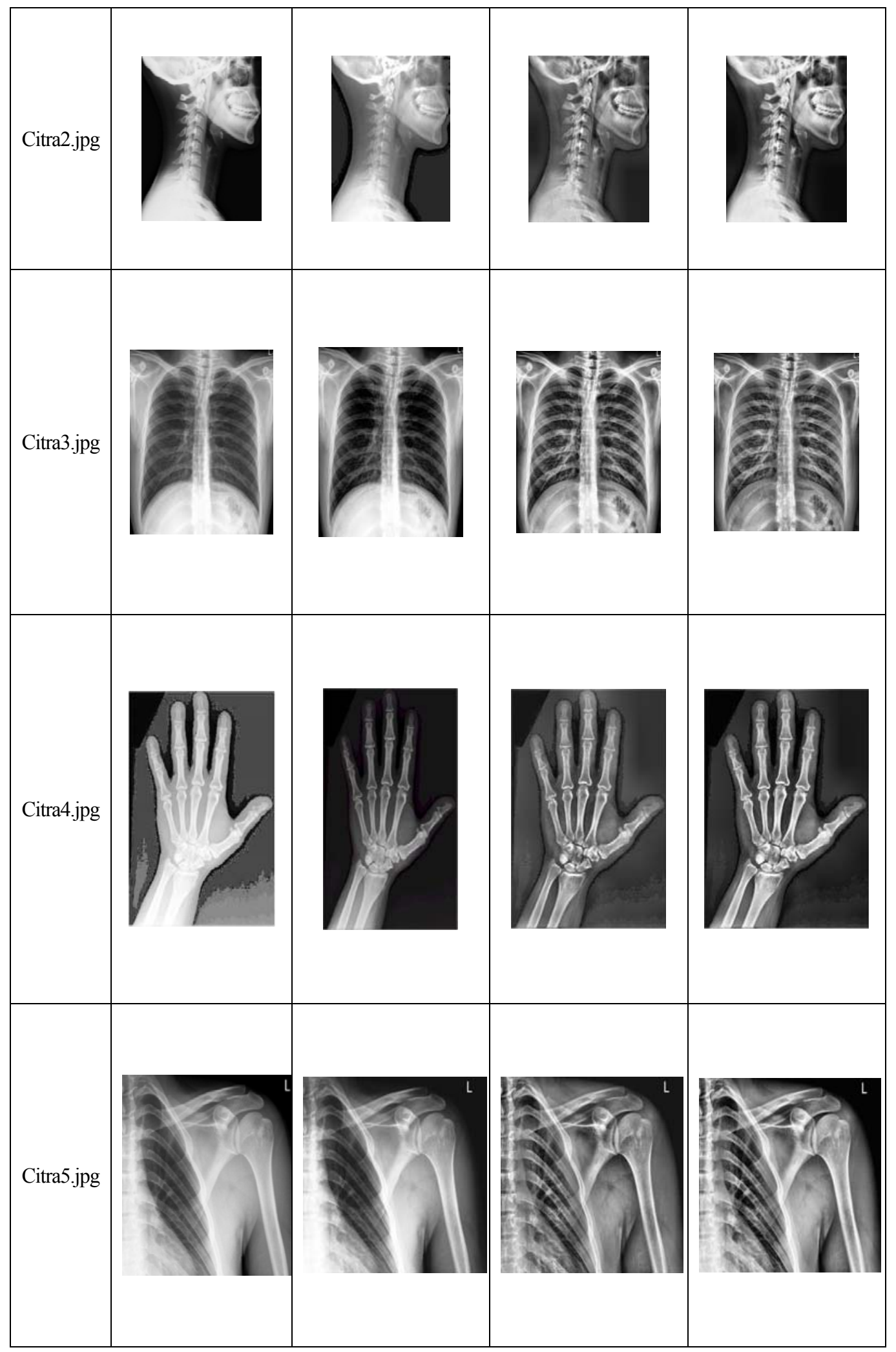

Gambar 1. Hasil Perbandingan Perbaikan Kualitas Citra antara HE, AHE dan CLAHE 


\subsection{Pengukuran Kualitas Citra}

Untuk mengevaluasi hasil komparasi metode berbasis histogram equalization, kandungan informasi yang digunakan sebagai ukuran perhitungan kualitas citra adalah perbandingan nilai eror piksel dari citra hasil perbaikan dengan citra asli. Kemudian dari hasil perbandingan perbaikan kontras citra menggunakan metode HE, AHE, dan CLAHE langkah selanjutnya dilakukan pengukuran kualitas hasil perbaikan kontras citra dengan menggunakan MSE (Mean Square Error) yang berfungsi untuk menghitung seberapa besar pergeseran data antara sinyal sumber dan sinyal hasil keluaran, dimana sinyal sumber dan sinyal hasil keluaran memiliki ukuran yang sama untuk mengetahui erorr dari citra hasil perbaikan [5]. Berikut rumus yang menjelaskan perhitungan MSE.

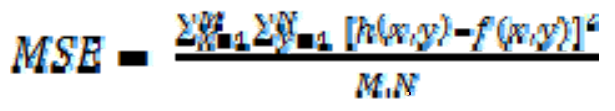

Dimana $f(x, y)$ adalah citra inputan, $h(x, y)$ adalah citra output, kemudian $\mathrm{M}$ dan $\mathrm{N}$ panjang dan lebar dari citra. Sebuah citra dengan nilai MSE yang medekati nilai 0 yaitu citra memiliki informasi nilai eror kecil dan dianggap memiliki kualitas yang lebih baik. Seperti yang ditunjukkan pada Tabel 1.

Tabel 1. Hasil Komparasi Pengukuran Mean Square Error dengan Metode HE, AHE dan CLAHE

\begin{tabular}{cccc}
\hline Nama Citra & $\boldsymbol{H E}$ & $\boldsymbol{A H E}$ & $\boldsymbol{C L A H E}$ \\
\hline Citra1.jpg & 108.6645 & 84.4690 & 65.8208 \\
Citra2.jpg & 41.7072 & 32.6204 & 7.3007 \\
Citra3.jpg & 108.0397 & 65.9003 & 28.3554 \\
Citra4.jpg & 15.2406 & 9.7180 & 1.2722 \\
Citra5.jpg & 121.5272 & 115.7128 & 99.9380 \\
Citra6.jpg & 20.0144 & 12.9739 & 3.1885 \\
Citra7.jpg & 130.3792 & 107.0977 & 90.7178 \\
Citra8.jpg & 78.2673 & 61.5649 & 15.4357 \\
Citra9.jpg & 58.7870 & 45.3007 & 7.0110 \\
Citra10.jpg & 76.7127 & 61.5422 & 20.0858 \\
Rata-Rata & $\mathbf{7 5 9 . 3 4 0}$ & $\mathbf{5 9 6 . 9 0 0}$ & $\mathbf{3 3 9 . 1 2 6}$ \\
\hline
\end{tabular}

\section{KESIMPULAN}

Penelitian ini menyajikan sebuah metode teknik histogram berbasis histogram equalization untuk peningkatan kontras citra medis untuk warna yang lebih terang. Pencahayaan berdasarkan pemerataan histogram sub citra asli terbukti merupakan teknik yang sangat efektif untuk mengurangi eror dengan persamaan (3) terhadap citra asli. Teknik perpotongan histogram pada metode CLAHE juga dikombinasikan dengan pemerataan histogram untuk memberikan kontrol piksel lebih baik dari perbaikan kontras yang mengarah ke peningkatan kualitas citra alami. Berdasarkan langkah-langkah perhitungan MSE yang telah dilakukan menggunakan metode CLAHE terbukti menunjukkan perolehan nilai rata-rata eror lebih kecil dibandingkan dengan menggunakan metode HE dan AHE. Seperti yang terlihat pada hasil komparasi bahwa contoh citra Citra4.jpg memiliki eror terkecil yaitu 1.2722 Sedangkan untuk hasil kualitas visual citra CLAHE menunjukkan hasil yang lebih baik dari pada metode He dan AHE untuk berbagai macam citra medis $x$-ray.

\section{DAFTAR PUSTAKA}

[1] Ketcham, D. 1974. "Image Enhancement Techniques for Cockpit Displays". Tech. rep., Hughes Aircraft.

[2] Hummel, R. 1977. "Image Enhancement by Histogram Transformation". Computer Graphics and Image Processing 6. 184195.

[3] Pizer, S. 1987. “Adaptive Histogram Equalization and Its Variations”. Computer Vision, Graphics, and Image Processing 39. 355-368.

[4] Zuiderveld, K. 1994. "Contrast Limited Adaptive Histogram Equalization”. In: P. Heckbert: Graphics Gems IV, Academic Press. ISBN 0-12-336155-9

[5] Acharya, 2005. "Image Processing: Principles and Applications", Wiley-Interscience. ISBN 0-471-71998-6

[6] Gonzalez, R., Woods, R. (1992). Digital Image Processing. New York: Addison-Wesley. 
Jurnal SIMETRIS, Vol 8 No 1 April 2017

ISSN: 2252-4983

[7] Sid-Ahmed, M. (1995) Image Processing: Theory, Algorithms, and Archi-tectures. New York: McGraw-Hill, ch. 4 . 